\title{
Humanin suppresses receptor activator of nuclear factor-kB ligand-induced osteoclast differentiation via AMP-activated protein kinase activation
}

\author{
Namju Kang, Ki Woo Kim, and Dong Min Shin* \\ Department of Oral Biology, BK21 PLUS Project, Yonsei University College of Dentistry, Seoul 03722, Korea
}

\section{ARTICLE INFO}

Received July 12, 2019

Revised July 30, 2019

Accepted July 30, 2019

\section{*Correspondence \\ Dong Min Shin \\ E-mail: dmshin@yuhs.ac}

Key Words

AMP-activated protein kinase

Humanin

Osteoclastogenesis

Receptor activator of nuclear factor- $\mathrm{KB}$ ligand

\begin{abstract}
Humanin (HN) is a mitochondrial peptide that exhibits cytoprotective actions against various stresses and diseases. HN has been shown to induce the phosphorylation of AMP-activated protein kinase (AMPK), which is a negative regulator of receptor activator of nuclear factor- $\kappa B$ ligand (RANKL). However, the role of $H N$ in osteoclastogenesis or other skeletal disorders remains unknown. Here, we examined whether $\mathrm{HN}$ regulates osteoclastogenesis via AMPK activation using bone marrowderived macrophage (BMM) cultures. Our results show that HN inhibited RANKL-induced osteoclast formation and reduced the expression of genes involved in osteoclastogenesis, including nuclear factor of activated T-cells cytoplasmic 1, osteoclastassociated receptor, cathepsin $\mathrm{K}$, and tartrate-resistant acid phosphatase. Moreover, $\mathrm{HN}$ increased the levels of phosphorylated AMPK protein; compound C, an AMPK inhibitor, recovered $\mathrm{HN}$-induced osteoclast differentiation. In addition, we found that $\mathrm{HN}$ significantly decreased the levels of RANKL-induced reactive oxygen species in BMMs. Therefore, these results indicate that HN plays an important role in osteoclastogenesis and may function as an inhibitor of bone disorders via AMPK activation.
\end{abstract}

\section{INTRODUCTION}

Bone is a mineralized connective tissue that is made up of cells, vessels, and calcium-containing crystals; it provides shape, protection, and support for body structures [1]. Bone undergoes continuous remodeling for healing and adaptation. Bone remodeling is continuously replaced by new tissue, requires interactions between bone-resorbing osteoclasts and bone-forming osteoblasts [2,3]. An imbalance between these cell types can result in several bone diseases, including Paget's diseases, osteoporosis, and osteopetrosis [4].

Osteoclasts are derived from hematopoietic cells of a mononuclear lineage and mediate bone loss. Both osteoclast formation and function are regulated by macrophage colony-stimulating factor (M-CSF) and receptor activator of nuclear factor- $\kappa \mathrm{B}$ ligand
(RANKL) [5]. M-CSF is critical for the proliferation of osteoclast progenitors, whereas RANKL binds to its receptor (RANK) in osteoclast precursors, inducing osteoclast differentiation [1]. Thus, the osteoclast remains a potential therapeutic target for the treatment of osteoporosis and other resorptive bone diseases.

AMP-activated protein kinase (AMPK) is a cellular energy sensor in eukaryotes that is activated when intracellular ATP production decreases [6]. Previous studies have indicated that AMPK is a negative regulator of RANKL-induced osteoclast differentiation $[7,8]$. Moreover, the mitochondria-derived peptide (MDP), MOTS-c, suppresses ovariectomy-induced bone loss via AMPK activation [9]. MDPs are retrograde signaling molecules that include humanin (HN), MOTS-c, and small humanin-like peptides. HN, the first MDP discovered, is a potential therapeutic agent for Alzheimer's disease [10]. In pancreatic $\beta$-cells, HN (c) (i) (S)

This is an Open Access article distributed under the terms of the Creative Commons Attribution Non-Commercial License, which permits unrestricted non-commercial use, distribution, and reproduction in any medium, provided the original work is properly cited. Copyright $\odot$ Korean J Physiol Pharmacol, pISSN 1226-4512, elSSN 2093-3827
Author contributions: N.K. designed the study and performed experiments. K.W.K. contributed to data interpretation. D.M.S. drafted and revised the manuscript. 
induces the phosphorylation of AMPK-like MOTS-c [11]. HN also regulates cellular processes via the CNTFR/WSX-1/gp130 trimeric receptor. Interestingly, activation of this receptor leads to stimulation of the STAT3 signaling pathway, which plays a negative role in regulating osteoclastogenesis [12,13]. In addition, HN protein levels in skeletal muscle increase after resistance training in the men with prediabetes and patients with coronary endothelial dysfunction have reduced levels of $\mathrm{HN}[14,15]$. These studies suggest a physiological significance to study the role of $\mathrm{HN}$ in various conditions, but endogenous regulation of $\mathrm{HN}$ under physiological conditions in bone is not yet established.

Previous studies report that stimulation of bone marrowderived macrophages (BMMs) by RANKL transiently induces the production of intracellular reactive oxygen species (ROS). Moreover, ROS mediate RANK signaling during osteoclast differentiation $[16,17]$. HN is known to protect against mitochondrial dysfunction induced by endoplasmic reticulum stress. HN directly inhibits oxidative stress at the mitochondrial membrane [18]. However, no studies have examined the relationship between $\mathrm{HN}$ and osteoclasts. We therefore investigated the regulatory mechanism by which HN exerts its effects on RANKL-induced osteoclast differentiation.

\section{METHODS}

\section{Reagents}

HN were synthesized by Anygen (Gwangju, Korea) and were characterized as having $>99 \%$ purity by high-performance liquid chromatography. The amino acid sequence of $\mathrm{HN}$ was followed as: Met Ala Pro Arg Gly Phe Ser Cys Leu Leu Leu Leu Thr Ser Glu Ile Asp Leu Pro Val Lys Arg Arg Ala. The peptides were dissolved in double-distilled $\mathrm{H}_{2} \mathrm{O}$ and aliquots were frozen at $-20^{\circ} \mathrm{C}$. Cell culture media, alpha-minimum essential medium ( $\alpha$-MEM) was obtained from GE Healthcare Life Sciences (Marlborough, MA, USA). Fetal bovine serum (FBS) and antibiotic-antimycotic were purchased from Gibco (Grand Island, NY, USA). M-CSF was purchased from PeproTech (Rocky Hill, NJ, USA) and RANKL was purchased from R\&D Systems (Minneapolis, MN, USA). Compound $\mathrm{C}$ was purchased from Cayman Chemical (Ann Arbor, MI, USA). Specific antibody against NFATc1 was obtained from Santa Cruz Biotechnology (Santa Cruz, CA, USA), Tubulin was obtained from Developmental Studies Hybridoma Bank (Iowa City, IA, USA), and Actin was obtained from Sigma-Aldrich (St. Louis, MO, USA). Antibodies against AMPK, phosphor (p)AMPK were obtained from Cell Signaling (Beverly, MA, USA).

\section{Cell culture}

Mouse bone marrow cells were isolated from 4-6 week old male ICR mice (Nara Biotech, Seoul, Korea) by flushing the fe- murs and tibias with $\alpha$-MEM. The cells were cultured overnight in $\alpha$-MEM with $10 \%$ FBS and $1 \%$ antibiotic-antimycotic reagent and incubated in $5 \% \mathrm{CO}_{2}$ incubator. Non-adherent cells were collected and seeded on adequate number of plates with M-CSF. After 3 days, non-adherent cells were washed out with fresh media, and the adherent cells were used as BMMs. M-CSF was treated at $30 \mathrm{ng} / \mathrm{ml}$ and RANKL was treated at $50 \mathrm{ng} / \mathrm{ml}$ concentration in $\alpha$-MEM.

\section{Tartrate-resistant acid phosphatase (TRAP) staining}

BMMs were seeded in 48-well plates at a concentration of $3 \times$ $10^{4}$ cells per well and cultured in $\alpha$-MEM containing $10 \%$ FBS with M-CSF, RANKL and with or without different concentrations of $\mathrm{HN}(0,1,5 \mu \mathrm{M})$. The culture medium was replaced every 2 days. After 6 days, a TRAP staining was performed to confirm the cell differentiation rate. TRAP ${ }^{+}$cells were stained using a Leukocyte Acid Phosphate Assay Kit (Sigma-Aldrich) by following the manufacturer's procedure. $\mathrm{TRAP}^{+}$multinucleated cells (containing $\geq 3$ nuclei) were counted.

\section{Cell viability assay}

BMMs were cultured in the medium with $30 \mathrm{ng} / \mathrm{ml}$ of M-CSF and $50 \mathrm{ng} / \mathrm{ml}$ of RANKL with or without HN at indicated concentrations in a 96-well plate. CellTiter $96 \mathrm{AQ}_{\text {ueous }}$ One Solution (Promega, Madison, WI, USA) was used to determine the cell viability following the manufacturer's instructions. Cell viability was measured at the wavelength of $490 \mathrm{~nm}$ using a 96-well plate reader.

\section{Western blot}

Cellular proteins were extracted in RIPA buffer (Tech \& Innovation, Seoul, Korea) and the amounts were measured by using Pierce BCA Protein Assay Kit (Thermo Fisher Scientific, Waltham, MA, USA). Proteins were separated with $8 \%$ or $10 \%$ SDS-PAGE and transferred to polyvinylidene difluoride membranes (Immobilon-P; Millipore Corp., Bedford, MA, USA). The membranes were blocked for $1 \mathrm{~h}$ at room temperature with 5\% nonfat skim milk in Tris-buffered saline (TBS) containing 0.1\% Tween-20 (TBS-T) and then probed with specific antibodies in $5 \%$ BSA in TBS-T overnight at $4^{\circ} \mathrm{C}$. The primary specific antibodies used were as follows: NFATc1 $(1: 750)$, AMPK $(1: 2,000)$, p-AMPK $(1: 2,000)$, Actin $(1: 1,000)$, and Tubulin $(1: 5,000)$. Membranes were then incubated for $1 \mathrm{~h}$ at room temperature with horseradish peroxidase-conjugated secondary antibodies. The antigen-antibody complexes were detected with an ECL Prime Western Blotting Detection Reagent (Amersham Biosciences, Piscataway, NJ, USA). Quantification was performed by densitometry using ImageJ (National Institutes of Health, https:// imagej.nih.gov/ij/) . 


\section{Real-time PCR analysis}

Total RNA was isolated by using Trizol reagent (Thermo Fisher Scientific) according to the manufacturer's instruction. cDNA was reverse transcribed from $2 \mu \mathrm{g}$ of RNA using the MultiScribe Reverse Transcriptase (Applied Biosystems, Foster City, CA, USA). PCR amplification was performed in a $20-\mu \mathrm{l}$ reaction mix containing cDNA, $0.2 \mu \mathrm{M}$ primers, and $10 \mu \mathrm{l}$ of SensiFAST SYBR Hi-ROX Kit (Bioline, London, UK). Gene expression levels were measured using real-time RT-PCR with an StepOnePlus Real-Time PCR System (Applied Biosystems). The relative amount of mRNA normalized to HPRT was calculated using the deltadelta method. The following primers were used: NFATc1 forward: 5'-CAAGTCTCACCACAGGGCTCACTA-3', reverse: 5'-GCGTGAGAGGTTCATTCTCCAAGT-3'; osteoclast-associated receptor (OSCAR) forward: 5'-CCTAGCCTCATACCCCCAG-3', reverse: 5'-CGTTGATCCCAGGAGTCACAA-3'; cathepsin K (CTSK) forward: 5'-AAGAAGACTCACCAGAAGCA-3', reverse: 5'-TCCAGGTTATGGGCAGAGATT-3'; TRAP forward: 5'-GCAACATCCCCTGGTATGTG-3', reverse: 5'-GCAAACGGTAGTAAGGGCTG-3'; HPRT forward: 5'-GCCTAAGATGAGCGCAAGTTG-3', reverse: 5'-TACTAGGCAGATGGCCACAGG-3'.

\section{ROS generation assay}

The cells were seeded in 12-well plate with cover glass at a density of $0.15 \times 10^{6} /$ well. ROS was detected using the fluorescent probe 5-(and 6)-carboxy-2', $7^{\prime}$-dichlorofluorescin diacetate (DCF$\mathrm{DA})$. The cells were exposed to $10 \mu \mathrm{M}$ DCF-DA for $20 \mathrm{~min}$ and examined with a laser-scanning confocal microscope (model
LSM 510; Carl Zeiss, Jena, Germany) with a green fluorescent protein filter set. The mean relative fluorescence intensity for each field was measured with a Zeiss vision system and averaged.

\section{Statistical analysis}

Data were expressed as mean \pm standard deviation from at least 3 independent experiments. Statistical significance was determined by using a paired Student's t-test. Statistical significance was set at $\mathrm{p}<0.05$ level.

\section{RESULTS}

\section{HN inhibits RANKL-induced osteoclast differentiation}

To investigate the effects of HN on RANKL-induced osteoclast differentiation, BMMs were incubated with the indicated concentrations of $\mathrm{HN}$ in the presence of $30 \mathrm{ng} / \mathrm{ml} \mathrm{M-CSF}$ and $50 \mathrm{ng} / \mathrm{ml}$ RANKL for 5 days. HN treatment of BMMs dramatically inhibited the formation of TRAP ${ }^{+}$osteoclasts (Fig. 1A). The number of TRAP $^{+}$osteoclasts ( $\geq 3$ nuclei) was decreased by HN in a dosedependent manner. In addition, using an MTS assay, we observed that there were no cytotoxic effects if the concentration of $\mathrm{HN}$ used was less than $5 \mu \mathrm{M}$ (Fig. 1B). These results demonstrate that $\mathrm{HN}$ suppresses osteoclast differentiation.

\section{HN inhibits osteoclast-specific gene expression}

To further assess the inhibitory activity of HN on osteoclastogenesis, we assessed the mRNA expression levels of osteoclast

A

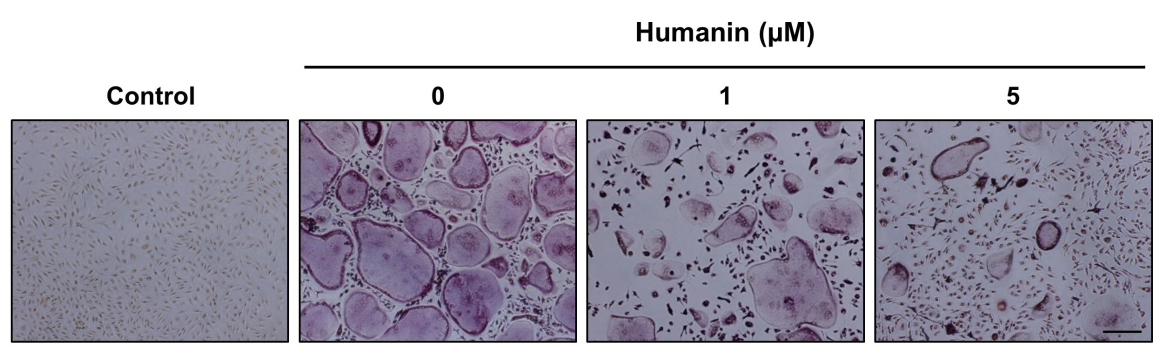

B

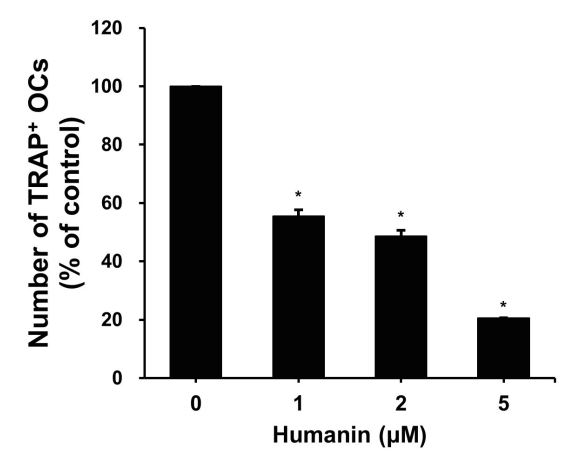

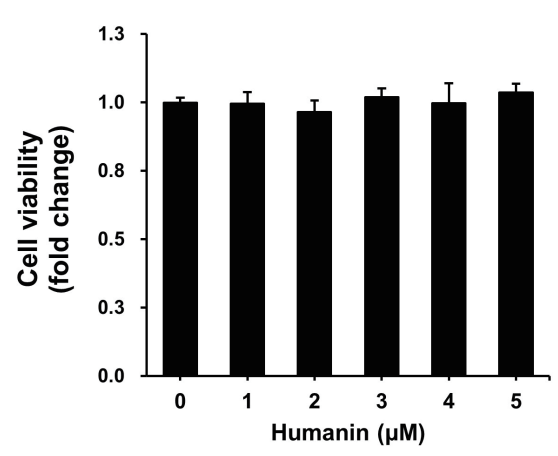

Fig. 1. Effects of humanin (HN) on receptor activator of nuclear factorKB ligand (RANKL)-induced osteoclast differentiation. (A) Bone marrowderived macrophages (BMMs) were cultured in the presence of macrophage colony-stimulating factor (M-CSF) (30 $\mathrm{ng} / \mathrm{ml})$, RANKL $(50 \mathrm{ng} / \mathrm{ml})$, and the indicated concentrations of HN for 6 days. Cells were stained for tartrate-resistant acid phosphatase (TRAP). Scale bar, 500 $\mu \mathrm{m}$. (B) Numbers of TRAP $^{+}$multinucleated cells were counted ( $\geq 3$ nuclei). BMMs were seeded into 96 -well plates and incubated with various concentrations of HN. Cell viability was measured by the MTS assay. OCs, osteoclasts. ${ }^{*} p<$ 0.05 compared with control. 
markers. Results of RT-PCR analysis revealed that HN caused a reduction in the mRNA levels of NFATc1, which is an important nuclear transcriptional factor in osteoclastogenesis. Furthermore, the mRNA levels of molecules downstream of NFATc1, such as OSCAR, CTSK, and TRAP, were significantly reduced by HN during osteoclast differentiation (Fig. 2A). Next, we investigated NFATcl protein levels during osteoclast differentiation; the protein levels of NFATcl were significantly reduced in HN-treated osteoclasts (Fig. 2B). Together, these results suggest that $\mathrm{HN}$ has the potential to suppress osteoclast formation.

\section{HN increases p-AMPK protein levels during osteoclast differentiation}

Based on previous findings that $\mathrm{HN}$ induces the phosphorylation of AMPK [11] and that AMPK is a negative regulator of RANKL-induced osteoclast differentiation $[7,8]$, we investigated whether AMPK links osteoclastogenesis with $\mathrm{HN}$. HN treatment significantly induced the phosphorylation of AMPK protein and increased the p-AMPK:AMPK ratio during RANKL-induced osteoclastogenesis (Fig. 3A). To confirm whether AMPK signaling regulates $\mathrm{HN}$-induced osteoclast differentiation, we used compound C, a known AMPK inhibitor [19]. The number of TRAP ${ }^{+}$ osteoclasts cultured with compound $\mathrm{C}$ recovered to the level of control that treated with RANKL only (Fig. 3B). These results suggest that $\mathrm{HN}$ suppresses osteoclast differentiation via AMPK activation.

\section{HN decreases ROS release during osteoclast differentiation}

RANKL increases the levels of intracellular ROS in BMMs [16]. We thus assessed whether HN could affect ROS production in osteoclast precursors after RANKL treatment. RANKL-induced ROS production, as measured using DCF-DA, was significantly diminished in HN-treated BMMs (Fig. 3C). These data indicate that RANKL-generated ROS production in osteoclast precursors is downregulated by $\mathrm{HN}$.

\section{DISCUSSION}

$\mathrm{HN}$, a novel MDP, was discovered by screening a cDNA library obtained from the brain of an Alzheimer's disease patient in 2001 [10]. HN acts as an extracellular ligand for a trimeric receptor consisting of CNTFR, the cytokine receptor WSX-1, and the transmembrane glycoprotein gp130 [20]. Via this trimeric receptor, HN regulates important cellular processes such as STAT3 activation, which is a negative regulator of osteoclast differentiation [13]. Moreover, HN protects cells from oxidative stress and hypoxia and is a promising therapeutic agent for the treatment of cardiovascular and Alzheimer's diseases in previous studies [21].
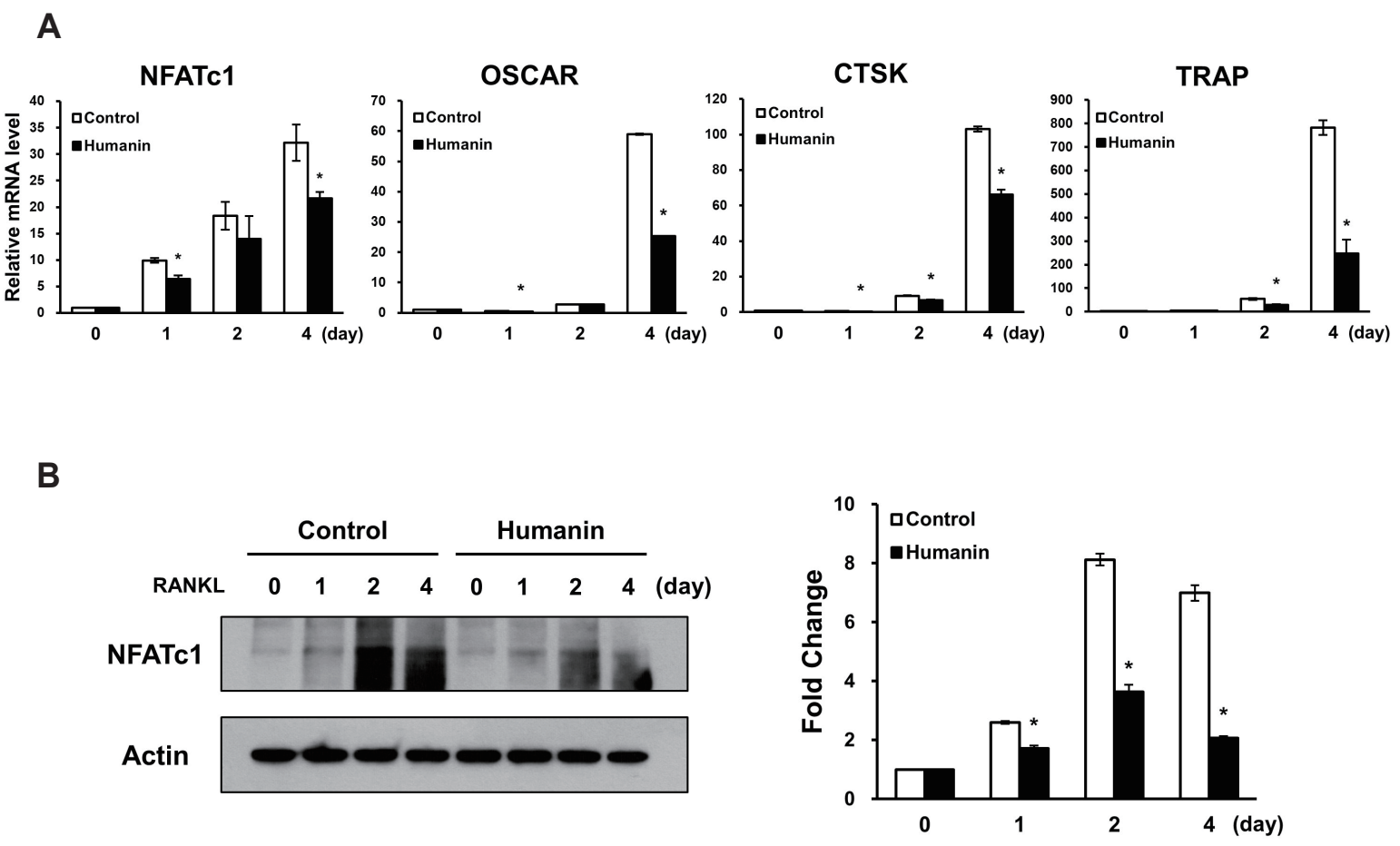

Fig. 2. Effects of humanin on the mRNA and protein levels of osteoclastogenesis-related genes. (A) The mRNA levels of receptor activator of nuclear factor- $\kappa B$ ligand (RANKL)-induced osteoclast differentiation markers were evaluated by quantitative RT-PCR. (B) NFATc1 protein levels were examined by Western blot analyses. OSCAR, osteoclast-associated receptor; CTSK, cathepsin K; TRAP, tartrate-resistant acid phosphatase. ${ }^{*} p<0.05$ compared with control. 


\section{A}
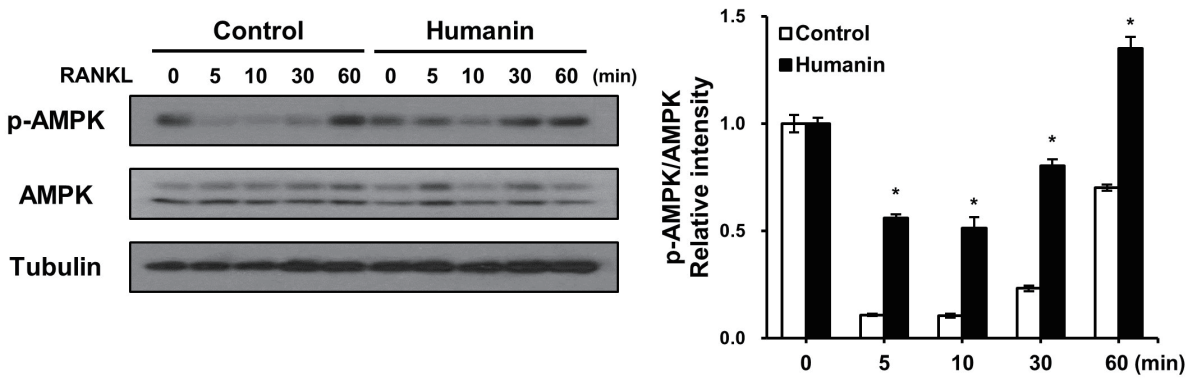

B
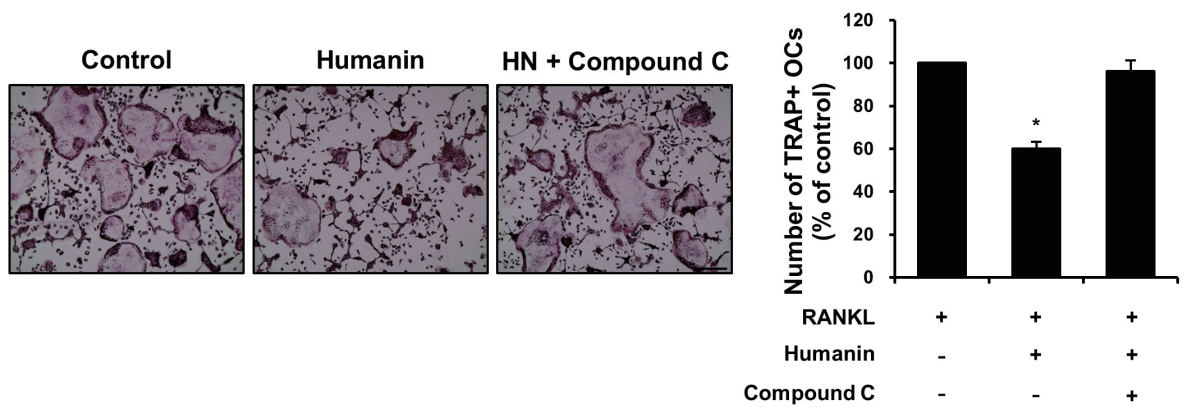

Fig. 3. Effects of humanin (HN) on AMP-activated protein kinase (AMPK) activation during osteoclast differentiation and receptor activator of nuclear factor-kB ligand (RANKL)induced reactive oxygen species production in bone marrow-derived macrophages (BMMs). (A) Western blot analysis of phosphor (p)-AMPK and AMPK during RANKL-induced osteoclastogenesis in untreated or HNtreated BMMs. The $\mathrm{p}-\mathrm{AMPK}: \mathrm{AMPK}$ ratio was calculated. (B) BMMs were treated
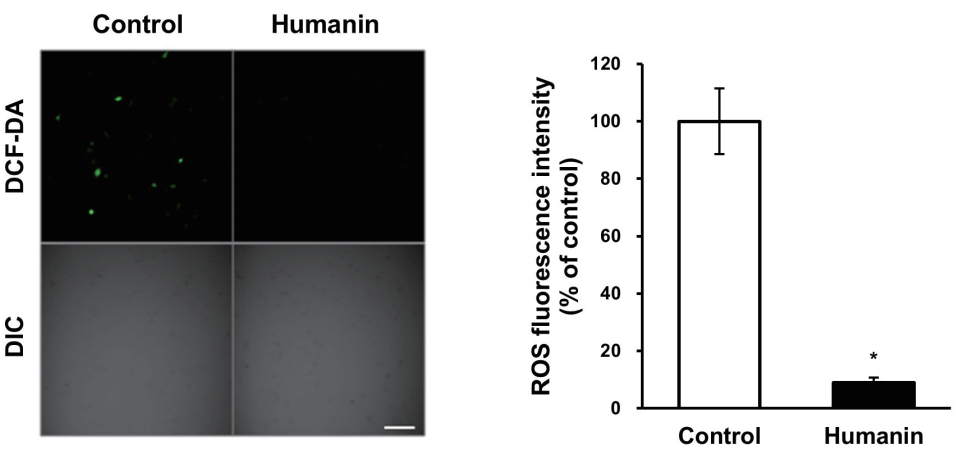
with or without $\mathrm{HN}$, and compound $\mathrm{C}$, and stained for tartrate-resistant acid phosphatase (TRAP). Numbers of TRAP ${ }^{+}$ multinucleated cells were counted $(\geq$ 3 nuclei). Scale bar, $500 \mu \mathrm{m}$. (C) BMMs were treated with RANKL $(50 \mathrm{ng} / \mathrm{ml})$ for $10 \mathrm{~min}$ and loaded with $10 \mu \mathrm{M}$ dichlorofluorescein diacetate (DCF-DA). Data are expressed relative to the value for control BMMs. Scale bar, $100 \mu \mathrm{m}$. OCs, osteoclasts. ${ }^{*} p<0.05$ compared with control.

However, the role of $\mathrm{HN}$ in osteoclastogenesis remains unknown. In the present study, we found that $\mathrm{HN}$ inhibited osteoclast differentiation in BMMs (Fig. 1A).

The skeleton is continuously remodeled via bone resorption by osteoclasts and bone formation by osteoblasts [2]. An imbalance in these cell types is a cause of bone diseases such as Paget's diseases, osteoporosis, and osteopetrosis [3,22]. Osteoclasts are multinucleated cells that are specialized in bone resorption and derived from hematopoietic cells of a mononuclear lineage [23]. Osteoclast differentiation is initiated by M-CSF and RANKL, which activate osteoclastic transcription factors [24]. M-CSF promotes the proliferation and survival of osteoclast precursors, and RANKL, which is expressed by osteoblasts, regulates the signaling pathway for osteoclast precursors to differentiate into osteoclasts [25]. RANKL/RANK binding initiates tumor necrosis factor receptor-associated factor 6 and downstream signaling pathways that include nuclear factor- $\kappa \mathrm{B}, \mathrm{c}$-Jun $\mathrm{N}$-terminal kinase, and extracellular signal-regulated kinase [26,27]. Additionally, NFATc1 is a downstream target of RANK and a master regulator of osteoclast differentiation $[28,29]$. NFATcl regulates osteoclastspecific genes, including OSCAR, CTSK, and TRAP [30]. Briefly, NFATcl cooperates with PU.1 and microphthalmia-associated transcription factor to elicit effects on the CTSK and OSCAR promoters [31]. In addition, the NFAT:AP-1 complex activates TRAP [32]. NFATc1 is an essential regulator, induced by RANKL signaling, of osteoclast differentiation. We thus confirmed the inhibition of NFATc1 protein and mRNA expression in HN-treated BMMs (Fig. 2). RANKL stimulation induced a signaling pathway that leads to generation of ROS during osteoclastogenesis $[16,17]$. Additionally, AMPK was known to suppress ROS in acute myeloid leukemia cells obtained from bone marrow [33]. Therefore, these findings and our data (Fig. 3C) suggest that ROS increased by RANKL is reduced via AMPK activation in HN treated BMMs and $\mathrm{HN}$ may have a protective role in osteoclast differentiation. 
AMPK is a central regulator of cellular energy homeostasis and is activated by the depletion of intracellular ATP [34]. AMPK has been studied as a possible therapeutic target for preventing diabetes and cancer over the last decade. For example, AMPK mediates the tumor-suppressor effects of LKB1, and its activation improves insulin sensitivity and glucose homeostasis [35]. Moreover, as AMPK consists of an $\alpha$ catalytic subunit ( $\alpha 1$ and $\alpha 2$ ), a $\beta$ subunit ( $\beta 1$ and $\beta 2)$, and a regulatory $\gamma$ subunit $(\gamma 1, \gamma 2$, and $\gamma 3)$ [36], the deletion of the AMPK $\alpha$ and $\beta$ subunits in mice has been reported to decrease bone mass in vivo. Additionally, a number of in vitro studies of AMPK have been conducted in bone cells $[9,37,38]$. Thus, AMPK is activated by osteoclast differentiation and plays a negative role in $\mathrm{TRAP}^{+}$osteoclast formation. Further, compound $\mathrm{C}$ has been used as a selective inhibitor of AMPK in cellular systems [19]. Our results show that the number of TRAP ${ }^{+}$osteoclasts cultured with compound $\mathrm{C}$ recovered to the level of control (Fig. 3B). These results suggest that $\mathrm{HN}$ suppresses osteoclast differentiation via AMPK activation.

In this study, we demonstrated that $\mathrm{HN}$ inhibited osteoclast differentiation and osteoclast-specific expression of the NFATc1, OSCAR, CTSK, and TRAP genes. Furthermore, our results revealed that $\mathrm{HN}$ increased the phosphorylation of AMPK in BMMs, suggesting that HN suppresses RANKL-induced osteoclast differentiation via AMPK activation. Therefore, our findings support the hypothesis that $\mathrm{HN}$ is potential therapeutic target for the treatment of bone loss in osteoporosis and bone diseases caused by osteoclasts.

\section{ACKNOWLEDGEMENTS}

This work was supported by the National Research Foundation of Korea (NRF) grant funded by the Korea government (MSIP) (NRF. 2016R1A5A2008630).

\section{CONFLICTS OF INTEREST}

The authors declare no conflicts of interest.

\section{REFERENCES}

1. Datta HK, Ng WF, Walker JA, Tuck SP, Varanasi SS. The cell biology of bone metabolism. J Clin Pathol. 2008;61:577-587.

2. Charles JF, Aliprantis AO. Osteoclasts: more than 'bone eaters'. Trends Mol Med. 2014;20:449-459.

3. Erkhembaatar M, Gu DR, Lee SH, Yang YM, Park S, Muallem S, Shin DM, Kim MS. Lysosomal $\mathrm{Ca}^{2+}$ signaling is essential for osteoclastogenesis and bone remodeling. J Bone Miner Res. 2017;32:385396.

4. Florencio-Silva R, Sasso GR, Sasso-Cerri E, Simões MJ, Cerri PS. Biology of bone tissue: structure, function, and factors that influence bone cells. Biomed Res Int. 2015;2015:421746.

5. Teitelbaum SL. Bone resorption by osteoclasts. Science. 2000;289: 1504-1508.

6. Mihaylova MM, Shaw RJ. The AMPK signalling pathway coordinates cell growth, autophagy and metabolism. Nat Cell Biol. 2011; 13:1016-1023.

7. Jeyabalan J, Shah M, Viollet B, Chenu C. AMP-activated protein kinase pathway and bone metabolism. J Endocrinol. 2012;212:277290.

8. Lee YS, Kim YS, Lee SY, Kim GH, Kim BJ, Lee SH, Lee KU, Kim GS, Kim SW, Koh JM. AMP kinase acts as a negative regulator of RANKL in the differentiation of osteoclasts. Bone. 2010;47:926-937.

9. Ming W, Lu G, Xin S, Huanyu L, Yinghao J, Xiaoying L, Chengming X, Banjun R, Li W, Zifan L. Mitochondria related peptide MOTS-c suppresses ovariectomy-induced bone loss via AMPK activation. Biochem Biophys Res Commun. 2016;476:412-419.

10. Hashimoto Y, Niikura T, Tajima H, Yasukawa T, Sudo H, Ito Y, Kita Y, Kawasumi M, Kouyama K, Doyu M, Sobue G, Koide T, Tsuji S, Lang J, Kurokawa K, Nishimoto I. A rescue factor abolishing neuronal cell death by a wide spectrum of familial Alzheimer's disease genes and Abeta. Proc Natl Acad Sci U S A. 2001;98:6336-6341.

11. Qin Q, Jin J, He F, Zheng Y, Li T, Zhang Y, He J. Humanin promotes mitochondrial biogenesis in pancreatic MIN6 $\beta$-cells. Biochem Biophys Res Commun. 2018;497:292-297.

12. Lee C, Yen K, Cohen P. Humanin: a harbinger of mitochondrialderived peptides? Trends Endocrinol Metab. 2013;24:222-228.

13. Zhang Z, Welte T, Troiano N, Maher SE, Fu XY, Bothwell AL. Osteoporosis with increased osteoclastogenesis in hematopoietic cellspecific STAT3-deficient mice. Biochem Biophys Res Commun. 2005;328:800-807.

14. Gidlund EK, von Walden F, Venojärvi M, Risérus U, Heinonen OJ, Norrbom J, Sundberg CJ. Humanin skeletal muscle protein levels increase after resistance training in men with impaired glucose metabolism. Physiol Rep. 2016;4:e13063.

15. Widmer RJ, Flammer AJ, Herrmann J, Rodriguez-Porcel M, Wan J, Cohen P, Lerman LO, Lerman A. Circulating humanin levels are associated with preserved coronary endothelial function. Am J Physiol Heart Circ Physiol. 2013;304:H393-H397.

16. Lee NK, Choi YG, Baik JY, Han SY, Jeong DW, Bae YS, Kim N, Lee SY. A crucial role for reactive oxygen species in RANKL-induced osteoclast differentiation. Blood. 2005;106:852-859.

17. Kim MS, Yang YM, Son A, Tian YS, Lee SI, Kang SW, Muallem S, Shin DM. RANKL-mediated reactive oxygen species pathway that induces long lasting $\mathrm{Ca}^{2+}$ oscillations essential for osteoclastogenesis. J Biol Chem. 2010;285:6913-6921.

18. Sreekumar PG, Hinton DR, Kannan R. Endoplasmic reticulummitochondrial crosstalk: a novel role for the mitochondrial peptide humanin. Neural Regen Res. 2017;12:35-38.

19. Liu X, Chhipa RR, Nakano I, Dasgupta B. The AMPK inhibitor compound $\mathrm{C}$ is a potent AMPK-independent antiglioma agent. Mol Cancer Ther. 2014;13:596-605.

20. Matsuoka M, Hashimoto Y. Humanin and the receptors for humanin. Mol Neurobiol. 2010;41:22-28.

21. Ikonen M, Liu B, Hashimoto Y, Ma L, Lee KW, Niikura T, Nishimoto I, Cohen P. Interaction between the Alzheimer's survival peptide humanin and insulin-like growth factor-binding protein 3 regulates cell survival and apoptosis. Proc Natl Acad Sci U S A. 
2003;100:13042-13047.

22. Yang YM, Kim MS, Son A, Hong JH, Kim KH, Seo JT, Lee SI, Shin DM. Alteration of RANKL-induced osteoclastogenesis in primary cultured osteoclasts from SERCA2 ${ }^{+/}$mice. J Bone Miner Res. 2009;24:1763-1769.

23. Boyle WJ, Simonet WS, Lacey DL. Osteoclast differentiation and activation. Nature. 2003;423:337-342.

24. Feng X, Teitelbaum SL. Osteoclasts: new insights. Bone Res. 2013; 1:11-26.

25. Teitelbaum SL. Osteoclasts, integrins, and osteoporosis. J Bone Miner Metab. 2000;18:344-349.

26. Boyce BF, Xing L. Functions of RANKL/RANK/OPG in bone modeling and remodeling. Arch Biochem Biophys. 2008;473:139-146.

27. Son A, Kim MS, Jo H, Byun HM, Shin DM. Effects of inositol 1,4,5-triphosphate on osteoclast differentiation in RANKL-induced osteoclastogenesis. Korean J Physiol Pharmacol. 2012;16:31-36.

28. Takayanagi H, Kim S, Koga T, Nishina H, Isshiki M, Yoshida H, Saiura A, Isobe M, Yokochi T, Inoue J, Wagner EF, Mak TW, Kodama T, Taniguchi T. Induction and activation of the transcription factor NFATc1 (NFAT2) integrate RANKL signaling in terminal differentiation of osteoclasts. Dev Cell. 2002;3:889-901.

29. Park B, Yang YM, Choi BJ, Kim MS, Shin DM. Activation of G proteins by aluminum fluoride enhances RANKL-mediated osteoclastogenesis. Korean J Physiol Pharmacol. 2013;17:427-433.

30. Kim JH, Kim N. Regulation of NFATc1 in osteoclast differentiation.
J Bone Metab. 2014;21:233-241.

31. Sharma SM, Bronisz A, Hu R, Patel K, Mansky KC, Sif S, Ostrowski MC. MITF and PU.1 recruit p38 MAPK and NFATc1 to target genes during osteoclast differentiation. J Biol Chem. 2007;282:1592115929.

32. Takayanagi $\mathrm{H}$. The role of NFAT in osteoclast formation. Ann N Y Acad Sci. 2007;1116:227-237.

33. Saito Y, Chapple RH, Lin A, Kitano A, Nakada D. AMPK protects leukemia-initiating cells in myeloid leukemias from metabolic stress in the bone marrow. Cell Stem Cell. 2015;17:585-596.

34. Kim J, Yang G, Kim Y, Kim J, Ha J. AMPK activators: mechanisms of action and physiological activities. Exp Mol Med. 2016;48:e224.

35. Shackelford DB, Shaw RJ. The LKB1-AMPK pathway: metabolism and growth control in tumour suppression. Nat Rev Cancer. 2009; 9:563-575.

36. Hardie DG. AMP-activated/SNF1 protein kinases: conserved guardians of cellular energy. Nat Rev Mol Cell Biol. 2007;8:774-785.

37. Kanazawa I, Yamaguchi T, Yano S, Yamauchi M, Yamamoto M, Sugimoto T. Adiponectin and AMP kinase activator stimulate proliferation, differentiation, and mineralization of osteoblastic MC3T3-E1 cells. BMC Cell Biol. 2007;8:51.

38. Jang WG, Kim EJ, Bae IH, Lee KN, Kim YD, Kim DK, Kim SH, Lee $\mathrm{CH}$, Franceschi RT, Choi HS, Koh JT. Metformin induces osteoblast differentiation via orphan nuclear receptor SHP-mediated transactivation of Runx2. Bone. 2011;48:885-893. 